\title{
Information Technology in Environmental Monitoring for Territorial System Ecological Assessment
}

\author{
Oleksandr Trofymchuk ${ }^{1}$, Dmytro Kreta ${ }^{2}$, Mykyta Myrontsov $^{1}$, Viacheslav Okhariev ${ }^{1}$, Viktor Shumeiko ${ }^{1}$ and \\ Snizhana Zagorodnia ${ }^{1}$ \\ 1. Institute of Telecommunications and Global Information Space, National Academy of Science of Ukraine, Kyiv 03186, Ukraine \\ 2. Department of Lifting Vehicle Radio Technical Systems, Kharkiv Aviation Institute, National Aerospace University, Kharkiv 61070 , \\ Ukraine
}

\begin{abstract}
The environmental monitoring dataset of Rivne region territory (Ukraine) was analyzed using remote sensing technology and statistical analysis. The article reveals approaches to anthropogenic impact specificity assessment based on methods of correlation analysis. The information technology to assess soil quality based on satellite images decoding was created.
\end{abstract}

Key words: Environmental safety, anthropogenic impact, environmental monitoring, correlation analysis, remote sensing.

\section{Introduction}

Nowadays, adjustment natural resources management and environmental protection in accordance to the principles of sustainable development are one of the main objectives in ecological management of Ukraine [1]. Imperfections of ecological monitoring system and decision-making processes prevent it. This causes a lack of a comprehensive management system in this area and prevents both natural and anthropogenic disaster control. Concerning comprehensive assessment of anthropogenic impact to geographical unit, its intensity and specificity must adjust to the quantitative criteria that will make it possible to compare these characteristics in the spatial and temporal dimensions. The truth of the matter is due to the lack of standard system of environmental assessment for different components of the environment (air, water, land), making it necessary to use dimensionless indices which should lead multidimensional datasets.

The aim is to analyze the environmental monitoring datasets using statistical methods and remote sensing

Corresponding author: Viacheslav Okhariev, master, junior research associate, research field: environmental sciences. E-mail: okhariev.vo@gmail.com. technologies for their further usage in the cases of areal system assessment of environmental health.

\section{Methodology}

The authors propose to use algorithm including component analysis of anthropogenic impact. Its comprehensive assessment for selected geographical units is part of administrative area. Also, it implies classification of administrative districts based on results of such assessment. Block diagram of the algorithm is shown in Fig. 1.

Comprehensive environmental assessment has to be based on environmental monitoring data analysis. For general pattern, it is appropriate to use remote sensing technologies and methods of statistical analysis. It is necessary to diversify statistical information annually and seasonally. The authors propose to use correlation analysis tools to identify interdependencies of pollution parameters. This approach makes it possible to determine key factors and classify sources of anthropogenic impact on the degree of danger [2-3]. The authors used Pearson correlation analysis method to analyze data of atmosphere and hydrosphere pollution in Rivne region (Ukraine). 


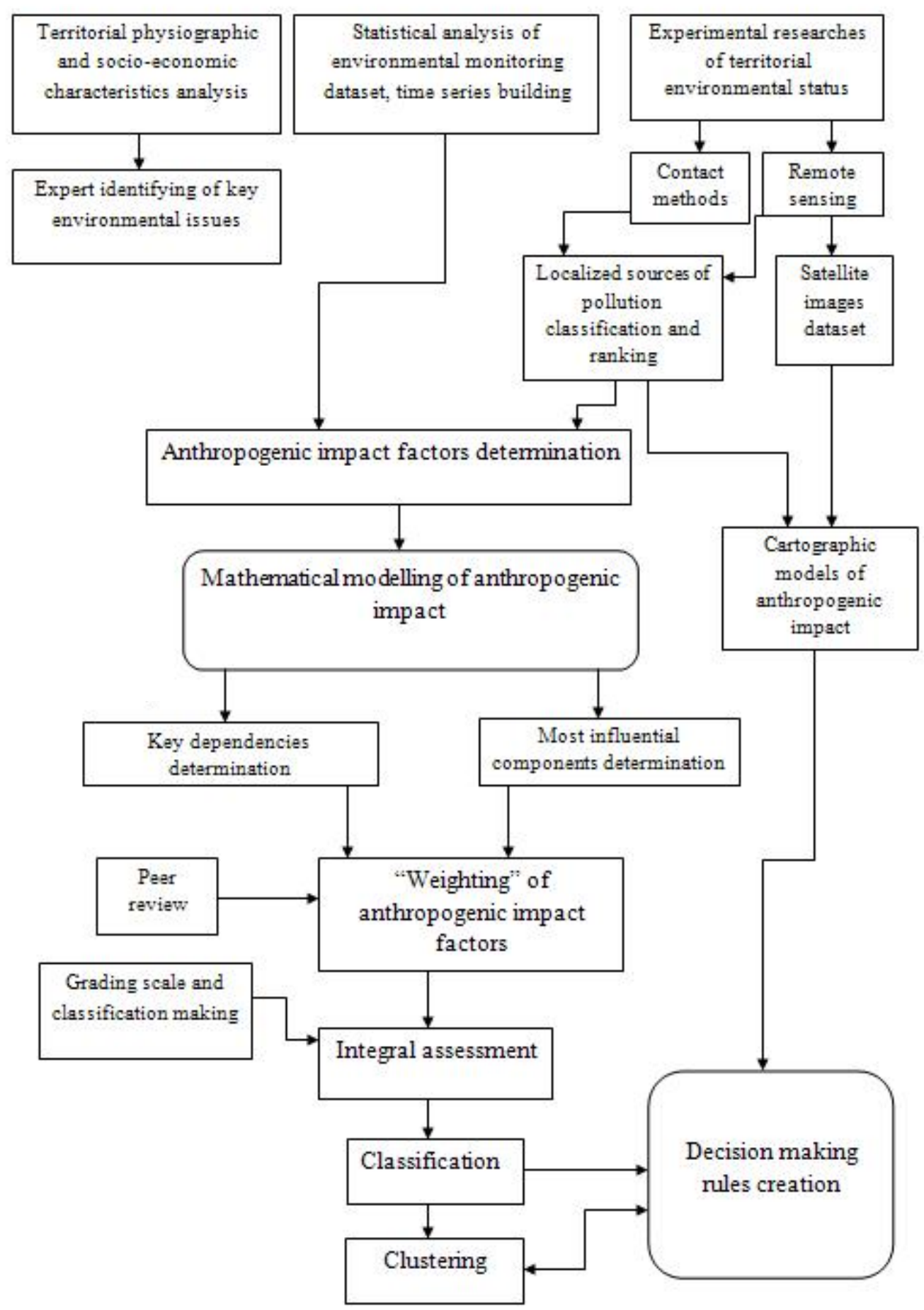

Fig. 1 Block diagram of environmental system assessment.

According to this method, the formulas have the form:

$$
r_{X Y}=\frac{\operatorname{cov}_{X Y}}{\sigma_{X} \sigma_{Y}}=\frac{\sum(X-\bar{X})(Y-\bar{Y})}{\sqrt{\Sigma(X-\bar{X})^{2} \sum(Y-\bar{Y})^{2}}}
$$

where, $\operatorname{cov}_{X Y}$ is covariance values of $X$ and $Y, \sigma_{X} \sigma_{Y}$ is standart deviation for $X$ and $Y, \bar{X}=\frac{1}{n} \sum_{t=1}^{n} X_{t}$ and $\bar{Y}=\frac{1}{n} \sum_{t=1}^{n} Y_{t}$ are average values of samples.

"Window-method" is used to describe the dynamics of changes and to determine the trend of relationship 
between different components of anthropogenic impact. In this case, correlation coefficient is calculated for each measurement with the limited number of neighboring measurements for each process. Thus, the dynamics of relationship intensity can be analyzed.

\section{Results and Discussion}

The territory of Rivne region in Ukraine was selected for research. It should be noted that Rivne region is one of the most affected regions by Chernobyl nuclear disaster. Radioactive waste contaminated large areas of land resources, including agricultural. Also, in the process of extensive development of the agricultural sector, large areas were identified to agricultural significance in the second half of the 20th century. Thus, it was decided to intense inning by the system of reclamation channels, which faced with large areas with waterlogged soils. Gathering of these factors has led to significant anthropogenic disturbance of lands in Rivne region. Also, it is necessary to take the impact of industrial enterprises into account. Although Rivne region has never been a top area of hazardous industries location, there are a number of plants and factories which heavily pollute atmosphere, water resources and soils.

Actual information technology can provide speed, visibility and completeness of obtaining environmental information. When using such technologies, it is necessary to determine possible approaches to address such issues as improving land monitoring system, optimizing the sampling stations on the contents of anthropogenic soil contaminants location, improving the quality and speed of anthropogenic impact influence, and parameters of soil quality mapping [4-6].

The authors synthesized base of satellite images of Rivne region territory with different resolutions as a part of environmental space monitoring data analysis. Using digital images processing methods, localization of point pollutants (Fig. 2) and areas of eutrophication processes in water surface (Fig. 3) were performed.

In this paper, the authors propose a semi-quantitative method of humus content distant determination in the soil. It is based on data collection about spectral properties of soil with different humus content in the test region and the formalization of this information in the form of spectral libraries. Patterns were extrapolated to large areas of land. It was done by using satellite image classification, which has based on spectral angle algorithm [7-8].

It is known from experimental researches that humus content in soil is associated with its spectral brightness. With the increase of humus in the soil, spectral coefficients brightness decreases. The biggest optical difference between humus-rich soils and soils with low content of humus is observed in the near

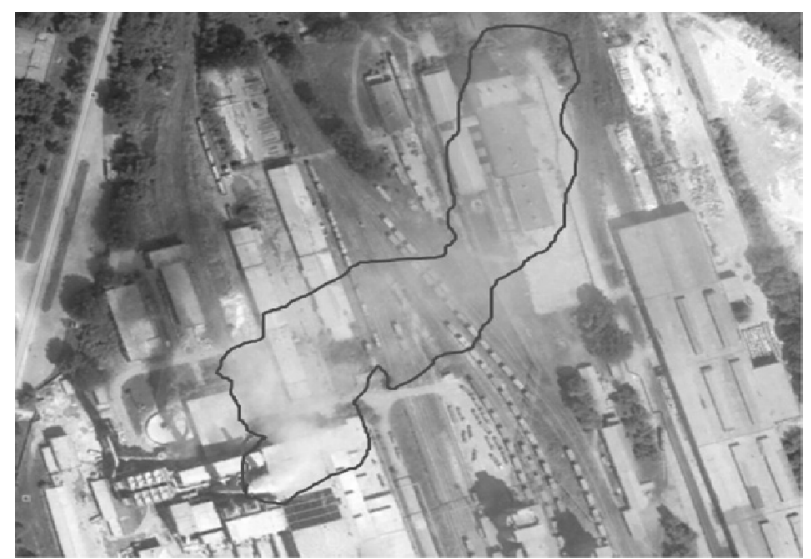

Fig. 2 Localization of the smoke-plume from a pollution point source (Volyn-Cement Factory, Zdolbuniv district, Rivne region).

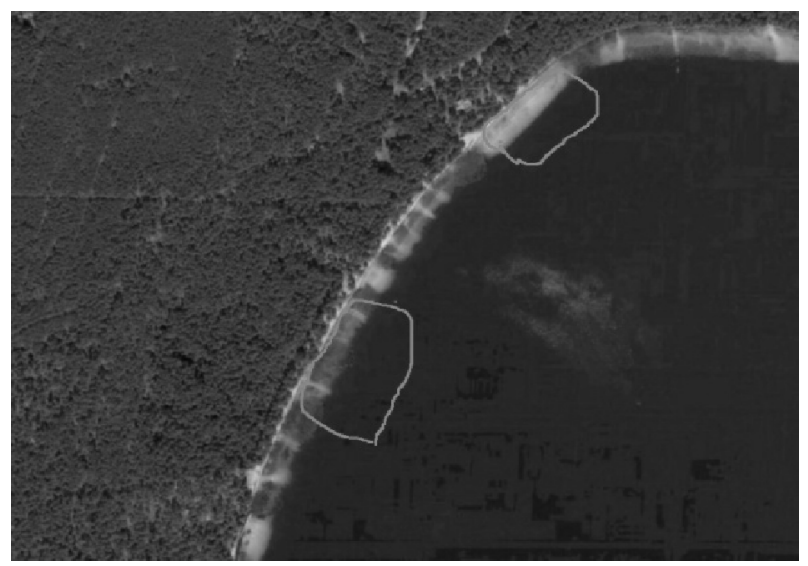

Fig. 3 Eutrophication on coastal areas of the lakes (Bile Lake, Volodymytets district, Rivne region). 
infrared spectrum $(0.75-1.3 \mu \mathrm{m})$.

To calculate the coefficients of equation, measurements of humus in 164 control points were conducted (Fig. 4). For each checkpoint, spectral brightness was determinated in the near infrared part of the spectrum and coefficient $K_{h}$ for different types of soil was calculated.

Using standard mathematical methods and software, regression equation pair $Y=F(U)$ was calculated. It was characterized by maximum value of the correlation coefficient and minimal residual variance. Relationship between humus content and spectral brightness coefficient is described by Eq. (2):

$$
G=K_{h} \times e^{-49.5 \times S B C}
$$

where, $G$ is total humus content (\%); SBC is spectral brightness coefficient for near-infrared channel $(0.75-1.3 \mu \mathrm{m}) ; K_{h}$ is ground ratio [9].

The results of correlation analysis of air and water pollution factors in the city of Rivne from 2012 to 2014 years (seasonal) are displayed in Figs. 5 and 6.
As can be seen in Figs. 5 and 6, correlation for carbon monoxide and anthropogenic dust is low, but stable with descending trend. Sharp downturn correlation of nitrogen oxide and formaldehyde may be explained by new outstanding monitoring pollution source.

Similar conclusions can be observed in the correlation analysis of pollution of Goryn and Ustia rivers. They flow in area of influence of Rivneazot - a large factory of nitrogen fertilizers production. Also, there are occasional high concentrations of such heavy metals as copper and hexavalent chromium, which may indicate a violation of environmental norms in some process flows.

Results of analysis indicate the presence of unaccounted pollution factors, which reduce correlation, as well as the non-linearity of anthropogenic impact processes. Also, it can be believed that the use of correlation analysis enables rapid diagnosis of the anthropogenic pressure dynamics to determinate new unaccounted factors of it.
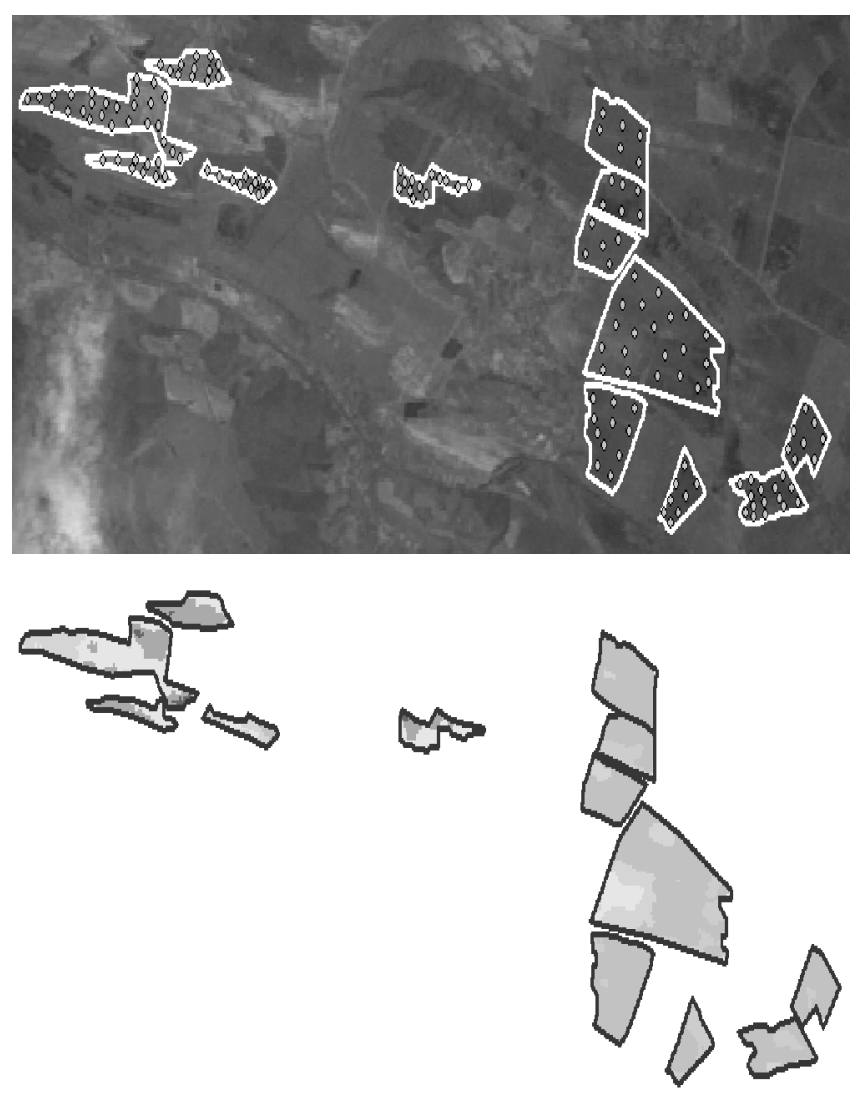

Fig. 4 Satellite image with localized areas for sampling. 

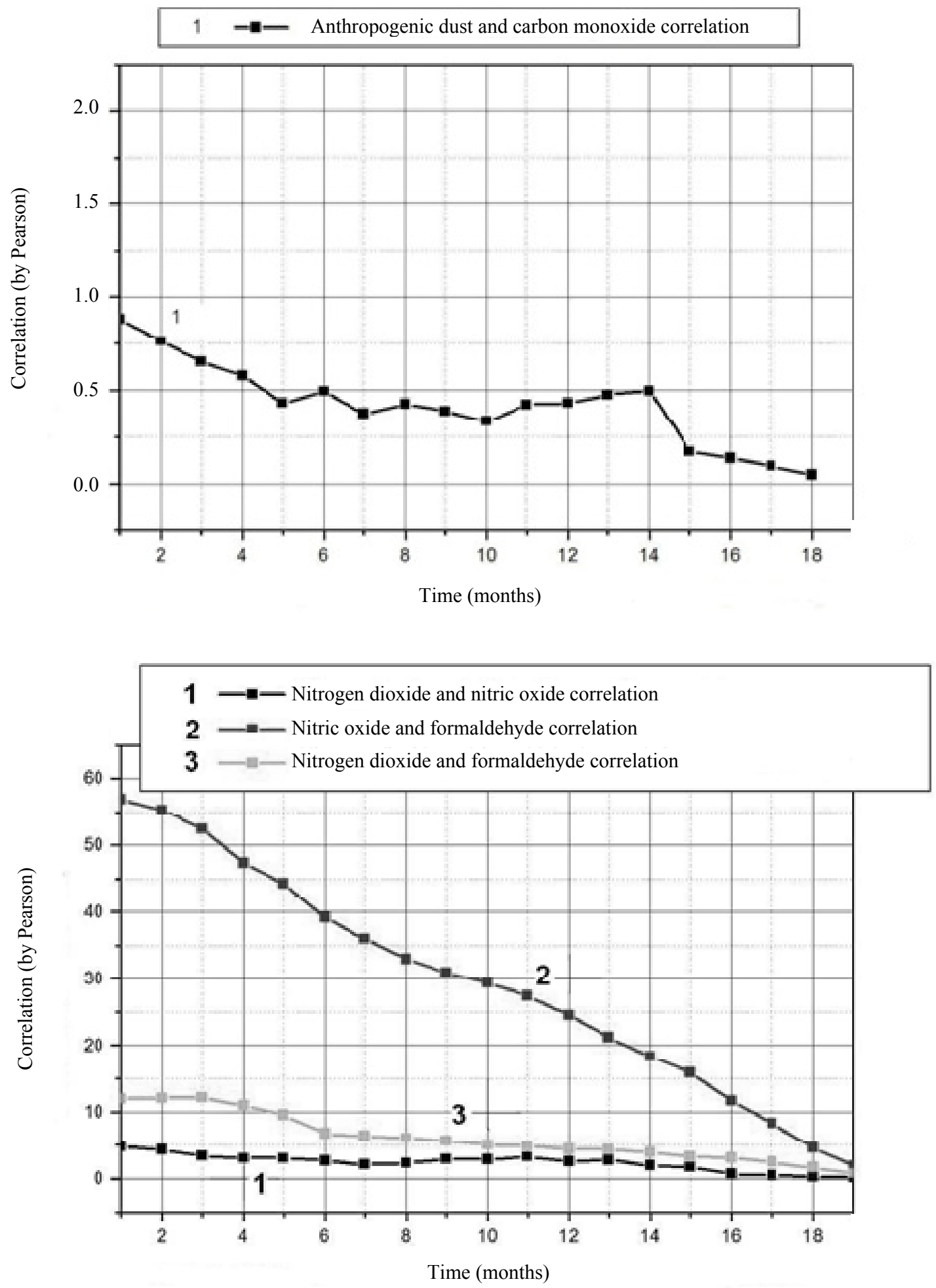

Fig. 5 Results of correlation analysis of air pollution factors in Rivne region (January 13-October 14). 


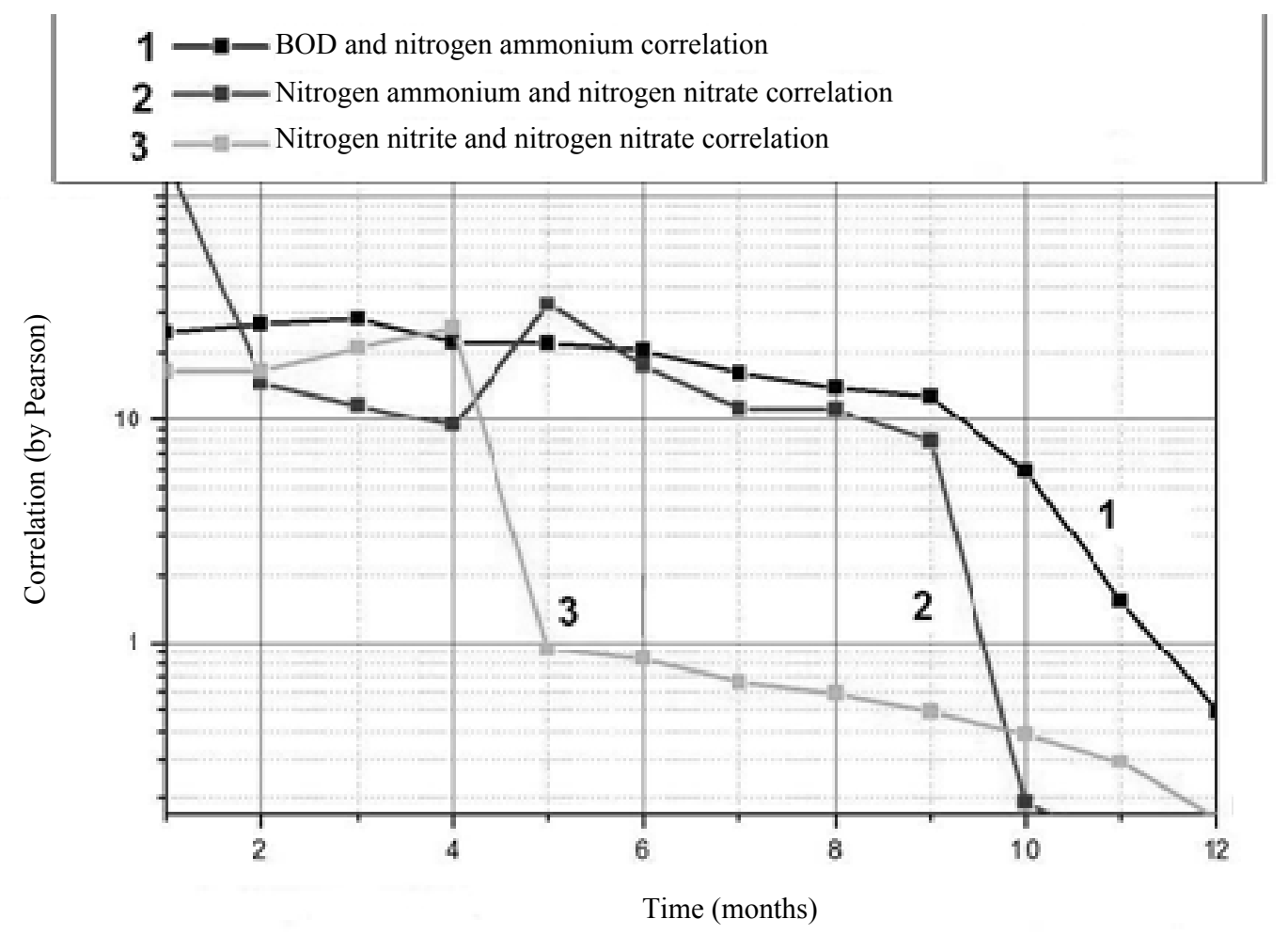

Fig. 6 Results of correlation analysis of water pollution factors in Rivne region (January 13-December 13).

\section{Conclusions}

The proposed approaches and algorithms make it possible to assess the relationships between the components of pollution, assuming that the environmental condition is determined by the intensity and specificity of anthropogenic impact. The authors proposed and tested method for rapid diagnosis of environmental monitoring which is based on an analysis of the dynamics of correlations between the parameters of pollution. Also, approach of assessment of humus content in soils was proposed and tested which is an important component of ecological and economic assessment of land resources.

\section{References}

[1] Verkhovna Rada of Ukraine. 2010. "Act of Ukraine about General Principles (Strategy) of State Environmental Policy till 2020." Verkhovna Rada of Ukraine. Accessed January 14, 2011. http://zakon2.rada.gov. ua/laws/show/2818-17.

[2] Ludwig, J. A., and Reynolds, J. F. 1988. Statistical Ecology: A Primer of Methods and Computing. New York: John Wiley and Sons.

[3] Dovgiy, S., Bidiuk, O., Trofymchuk, O., and Savenkov, O. 2011. Forecasting Methods in Decision Support Systems. Kyiv: Naukova Dumka.

[4] Krasovskiy, G., and Petrosov, V. 1999. Introduction to Space Environment Monitoring. Kharkiv: National Aerospace University Press.

[5] Grekov, L., Krasovskiy, G., and Trofymchuk, O. 2007. Space Monitoring of Land Pollution by Anthropogenic Dust. Kyiv: Naukova Dumka.

[6] Dovgiy, S., Lialko, V., Trofymchuk, O., and Fedorovskiy, O. 2001. Aerospace Geography Informatization. Kyiv: Naukova Dumka.

[7] Zborischuk, Y. 1994. Remote Sensing Methods for Monitoring and Inventory of Soil. Moscow: Moscow State University Press.

[8] Korolyov, Y. 2000. Spectral Methods and Control Environment. Moscow: Sputnik Plus.

[9] Lialko, V., and Popov, M. 2006. Multispectral Remote Sensing in Problems of Nature. Kyiv: Naukova Dumka. 